\title{
Dos Direitos de Aprendizagem e do Pacto Nacional pela Alfabetização na Idade Certa à Base Nacional Comum Curricular: o caso da alfabetização matemática
}

\author{
Emerson Rolkouski*
}

\begin{abstract}
Resumo
Este artigo tem como objetivo apresentar e discutir a Base Nacional Comum Curricular (BNCC) desde a escrita do documento Elementos Conceituais e Metodológicos para a Definição dos Direitos de Aprendizagem e Desenvolvimento do Ciclo de Alfabetização do Ensino Fundamental no ano de 2012 e do movimento formativo ocorrido nos anos de 2012 a 2017 disparado pelo Pacto Nacional pela Alfabetização na Idade Certa até a sua versão final (quarta versão) publicada em 2017, particularmente no que tange à alfabetização matemática. Para tanto, apresenta-se a estrutura dos documentos considerados, apontando, na sequência, as ausências, os afastamentos e novas aproximações presentes na Base Nacional Comum Curricular que resultaram em uma proposta reducionista, sobretudo no Ciclo de Alfabetização e particularmente na alfabetização matemática.

Palavras-Chave: Currículo; Alfabetização Matemática; Políticas Públicas; Formação de Professores.
\end{abstract}

\section{Learning Rights and the National Pact for Literacy in the Right Age to the National Curricular Common Base: the case of mathematical literacy}

\begin{abstract}
This article aims to present and discuss the National Curricular Common Base (BNCC) since the writing of the document Conceptual and Methodological Elements for the Definition of Rights of Learning and Development of the Literacy Cycle of Elementary School in the year of 2012 and a formative movement that occurred from the year 2012 to 2017 called National Pact for Literacy in the Right Age until its final version of BNCC published in 2017, particularly with concern to mathematical literacy. To achieve this aim, we present the structure of the documents considered, pointing to the absences, departures and new approaches present in the National Curricular Common Base that resulted in a reductionist proposal, especially in the Literacy Cycle and particularly in mathematical literacy.

Keywords: Curriculum; Mathematical Literacy; Public Policy; Teacher training.
\end{abstract}

\section{Introdução}

Em 2012, o Ministério da Educação (MEC), por meio da Secretaria de Educação Básica (SEB), da Diretoria de Currículos e Educação Integral (DICEI) e da Coordenação Geral do Ensino Fundamental (COEF), elaborou em conjunto com uma rede de especialistas e em diálogo com atores da comunidade escolar, o documento Elementos Conceituais e Metodológicos para a Definição dos Direitos de Aprendizagem e Desenvolvimento do Ciclo de Alfabetização do Ensino Fundamental. Tal escrita é respaldada pelo artigo 210 da Constituição Federal de 1988, que determina como dever do Estado, fixar conteúdos mínimos para o ensino fundamental, de maneira a assegurar a formação básica comum e respeito aos valores culturais e artísticos, nacionais e regionais" (BRASIL, 1988), e no Art. 9º, Inciso IV da Lei de Diretrizes e Bases da Educação Nacional (LDB) no 9.394, de 20 de dezembro de 1996 (BRASIL, 1996), que incumbe à União estabelecer, em colaboração com os Estados, o Distrito Federal e os Municípios, competências e diretrizes para a educação infantil, o ensino fundamental e o ensino médio, que norteiam os currículos e seus conteúdos mínimos, de modo a assegurar formação básica comum. Tal documento é tomado como base para o desenvolvimento do Pacto Nacional pela Alfabetização na Idade Certa, um programa de formação continuada de amplo alcance que tem como objetivo alfabetizar todas as crianças até os oito anos de idade.

Em 2014, a Lei 13.005, de 2014, institui o Plano Nacional de Educação. Tal documento estabelece 20 metas para melhorar a qualidade da Educação Básica, sendo que quatro delas se referem à Base Nacional Comum Curricular (BRASIL, 2014c). Em 2015 inicia-se formalmente a escrita da Base Nacional Comum Curricular (BNCC), que, depois de quatro versões, é publicada em 2017.

A descrição do processo de descolamento da versão final da BNCC, especificamente no que se refere ao Ciclo de Alfabetização e a alfabetização matemática, do documento Elementos Conceituais e Metodológicos para a Definição dos Direitos de Aprendizagem e Desenvolvimento do Ciclo de

*Endereço Eletrônico: rolkouski@uol.com.br 
Alfabetização do Ensino Fundamental e das discussões realizadas no âmbito do PNAIC é o objetivo desse artigo.

\section{Do documento Elementos Conceituais e Metodológicos para a Definição dos Direitos de Aprendizagem e Desenvolvimento do Ciclo de Alfabetização do Ensino Fundamental}

O documento Elementos Conceituais e Metodológicos para a Definição dos Direitos de Aprendizagem e Desenvolvimento do Ciclo de Alfabetização do Ensino Fundamental está organizado em duas partes.

A primeira parte se refere ao contexto do movimento curricular no Ensino Fundamental e do conceito de aprendizagem como direito humano e defende:

[...] a concepção de infância como universo singular dessa aprendizagem, tendo o currículo e o ciclo contínuo de aprendizagens como viabilização desses direitos. Tais conceitos são fundamentais para orientar essa trajetória, tendo em vista a avaliação e suas diferentes possibilidades de garantia dos Direitos (BRASIL, 2012, p. 8).

Já a segunda parte, trata de cada área do conhecimento com destaque para o componente curricular língua portuguesa, definindo seus direitos de aprendizagem, num "rol que compõe cerca de 30 direitos, 20 eixos estruturantes e 256 objetivos de aprendizagem".

Além de apresentar sua estrutura, considerase importante também apresentar a justificativa para a escrita do documento:

1. a LDB $n^{\text {o }} 93.94 / 1996$ sofreu significativas alterações;

2. a Lei 11.274 , de 06 de fevereiro de 2006, estabeleceu o ingresso da criança de seis anos de idade no Ensino Fundamental, ampliando-o para nove anos;

3. a Portaria Normativa $n^{\circ} 10$, de 24 de abril de 2007, que institui a "Provinha Brasil", explicita a avaliação do processo de alfabetização nos três primeiros anos do Ensino Fundamental de nove anos;

4. o Parecer da Câmara de Educação Básica (CEB) do Conselho Nacional de Educação (CNE) No 4, de 10 de junho de 2008, que institui que os três anos iniciais devem ser voltados à alfabetização e ao letramento;

5. o CNE/CEB elaborou Diretrizes Curriculares
Nacionais Gerais para a Educação Básica (DCNGEB);

6. o CNE/CEB elaborou novas Diretrizes Curriculares Nacionais para o Ensino Fundamental de Nove Anos (DCNEF);

7. o Programa Nacional do Livro Didático (PNLD) requer subsídios para que atenda às especificidades curriculares tanto das crianças de seis anos de idade neste novo Ensino Fundamental como para o Ciclo de Alfabetização;

8. o novo Plano Nacional de Educação (PNE) 2011-2020 está em processo de votação no Congresso Nacional;

9. os Cadernos de Formação do Pacto Nacional de Alfabetização na Idade Certa (2012) subsidiam a formação do professor alfabetizador, levando em conta concepções, conceitos, procedimentos, avaliações de aprendizagem, na direção de alfabetizar e letrar as crianças do Ciclo de Alfabetização (BRASIL, 2012, p. 12).

Destacamos a menção ao Ciclo de Alfabetização de três anos e dos Cadernos de Formação do Pacto Nacional pela Alfabetização na Idade Certa. Como se verá, tais justificativas foram ignoradas na versão final da BNCC.

$\mathrm{O}$ documento ainda apresenta uma série de ações que indicam que houve um processo longo e democrático de discussão com conselhos, comunidade acadêmica e escolar, desde o ano de 2004, na forma de encontros e seminários nacionais e internacionais. Desse processo resultou uma série de publicações que subsidiaram os participantes do "Grupo de Trabalho Fundamental em 2010/2011" sob a coordenação do MEC.

Tendo os documentos curriculares das secretarias de educação estaduais e de capitais brasileiras e o texto síntese produzido a partir dos encontros do "Grupo de Trabalho Fundamental em 2010/2011" como pontos de partida, uma equipe constituída por professores de 12 instituições públicas brasileiras de ensino superior e de pesquisa, estudantes de pós-graduação em Educação e Letras, estudantes de graduação em Pedagogia, e professores da educação básica ( 84 pessoas), que compõem a equipe de elaboração do Material de formação do Pacto Nacional pela Alfabetização na Idade Certa, construíram uma proposição de alguns direitos básicos de aprendizagem, que foi submetida à apreciação do Grupo de Trabalho Técnico para elaboração dos Direitos de Aprendizagem em Língua Portuguesa constituído em julho de 2012 no âmbito da Coordenação Geral do Ensino Fundamental (COEF). 
Em uma etapa posterior, o grupo de trabalho citado acima promoveu discussões sobre o documento base, com profissionais de secretarias de educação visitadas pela equipe pedagógica do MEC, os quais contribuíram, fazendo críticas e apresentando sugestões. Treze seminários foram realizados, contemplando profissionais de 1.029 sistemas de ensino. As contribuições foram sendo sistematizadas por técnicos do MEC e estudadas pelo Grupo de Trabalho Técnico para elaboração dos Direitos e Objetivos de Aprendizagem e Desenvolvimento, das áreas e seus respectivos componentes curriculares: Linguagem (Língua Portuguesa, Educação Física e Arte); Matemática; Ciências Humanas (História e Geografia); Ciências da Natureza que constituem o Ciclo de Alfabetização. Com base em tal sistematização, o documento era modificado. Outras contribuições foram oriundas dos debates travados com os participantes do VI Encontro do Grupo de Trabalho Fundamental Brasil, em 15 e 16 de agosto de 2012, realizado no MEC (BRASIL, 2012, p.17).

Como resultado desse processo, no âmbito da área de Matemática, definiram-se cinco direitos de aprendizagem:

I. Utilizar caminhos próprios na construção do conhecimento matemático, como ciência e cultura construídas pelo homem, através dos tempos, em resposta a necessidades concretas e a desafios próprios dessa construção.

II. Reconhecer regularidades em diversas situações, de diversas naturezas, compará-las e estabelecer relações entre elas e as regularidades já conhecidas.
III. Perceber a importância da utilização de uma linguagem simbólica universal na representação e modelagem de situações matemáticas como forma de comunicação.

IV. Desenvolver o espírito investigativo, crítico e criativo, no contexto de situaçõesproblema, produzindo registros próprios e buscando diferentes estratégias de solução.

V. Fazer uso do cálculo mental, exato, aproximado e de estimativas. Utilizar as Tecnologias da Informação e Comunicação potencializando sua aplicação em diferentes situações.

Os direitos assim elencados são desenvolvidos em cinco eixos estruturantes, cada um deles a ser garantido pelo trabalho com uma série de objetivos de aprendizagem, a saber:

- Números e Operações - correspondente a 44 objetivos de aprendizagem;

- Pensamento Algébrico - correspondente a 3 objetivos de aprendizagem;

- Espaço e Forma/Geometria correspondente a 18 objetivos de aprendizagem;

- Grandezas e Medidas - correspondente a 18 objetivos de aprendizagem;

- Tratamento da Informação - correspondente a 10 objetivos de aprendizagem.

Com vistas a ilustrarmos a profundidade com que tais objetivos são explicitados no documento, citamos (Quadro 1) um deles relativo ao eixo de Espaço e Forma/Geometria:

QUADRO 1: Exemplo de como os objetivos foram elencados

\begin{tabular}{|l|l|l|l|}
\hline $\begin{array}{l}\text { Eixo Estruturante } \\
\text { Espaço e Forma/Geometria } \\
\text { Objetivos de Aprendizagem }\end{array}$ & $1^{\mathbf{o}}$ Ano $^{1}$ & $2^{\mathbf{o}}$ Ano & $3^{\circ}$ Ano \\
\hline $\begin{array}{l}\text { Explicitar e/ou representar informalmente a posição de pessoas e objetos e I } \\
\text { dimensionar espaços, utilizando vocabulário pertinente nos jogos, nas brincadeiras e } \\
\text { nas diversas situações nas quais as crianças considerarem necessária essa ação, por } \\
\text { meio de desenhos, croquis, plantas baixas, mapas e maquetes, desenvolvendo noções } \\
\text { de tamanho, de lateralidade, de localização, de direcionamento, de sentido e de vistas. }\end{array}$ & & A & C \\
\hline
\end{tabular}

Fonte: Excerto do Documento Brasil (2012), adaptado pelo autor

Tais objetivos são explicitados de forma coerente ao referido pelo documento com indicações claras da concepção de infância e valorizando o aspecto lúdico. Tais referências são presentes na descrição dos outros objetivos, entendendo-se a superação da dicotomia forma conteúdo.

Como um movimento coerente de construção coletiva de currículo, em meados de 
2012, o Pacto Nacional pela Alfabetização na Idade Certa - PNAIC -, é lançado e tem sua implementação efetivada no fim do mesmo ano.

\section{Do Pacto Nacional pela Alfabetização na Idade Certa}

O PNAIC é um programa que tem o seu início em 2012 e tem, em seu histórico o lançamento de um edital que visava a constituir uma Rede Nacional de Formação de Professores (RENAFOR). A RENAFOR ${ }^{2}$ foi constituída em 2004 e reuniu centros de referência em formação de professores e hoje agrega 18 Instituições de Ensino Superior (IES). Tal histórico é relevante, pois ressalta o diálogo e a construção conjunta do programa junto às IES e veremos adiante, também junto às Secretarias de Educação e comunidade escolar.

Na sequência da criação da RENAFOR, o MEC inaugura um modelo de política pública de formação de professores de larga escala com o PróLetramento. Tal programa se difere de outros, pois o MEC teve a centralidade de algumas ações, como, por exemplo, o gerenciamento e oferta de bolsas, enquanto a formação dos professores era realizada de forma descentralizada pelas IES da RENAFOR.

O PNAIC também tem em seu histórico o PAIC - Programa de Alfabetização na Idade Certa do Ceará, que obteve um sucesso considerável. No entanto, e, fato importante para o nosso estudo, diferentemente do PAIC que estabelecia parcerias com Editoras privadas, o PNAIC, não sem embates, foi inteiramente desenvolvido por IES públicas.

Como o PNAIC tinha como objetivo atender a todos os professores do Ciclo de Alfabetização, foi necessário o convite a outras IES. No final de 2015, a rede de IES responsáveis pela formação no PNAIC era composta de mais de 30 universidades, sendo ao menos uma por estado.

De acordo com o livreto do PNAIC: O Pacto Nacional pela Alfabetização na Idade Certa é um compromisso formal assumido pelos governos federal, do Distrito Federal, dos estados e municípios de assegurar que todas as crianças estejam alfabetizadas até os oito anos de idade, ao final do $3^{\circ}$ ano do ensino fundamental (BRASIL, 2013, p. 13).

As ações do Pacto são realizadas em quatro eixos: Formação Continuada de Professores Alfabetizadores, Materiais Didáticos e Pedagógicos, Avaliações e Gestão, Controle e Mobilidade Social.
I. Formação Continuada de Professores Alfabetizadores: Curso presencial de 2 anos para os professores alfabetizadores, com carga horária de 120 horas por ano, com base no programa Pró-Letramento, cuja metodologia propõe estudos e atividades práticas. Os encontros com os professores alfabetizadores serão conduzidos por orientadores de estudo. Os orientadores de estudo são professores das redes, que farão um curso específico, com 200 horas de duração por ano, ministrado por universidades públicas. É recomendável que os orientadores de estudo sejam selecionados entre a equipe de tutores formados pelo PróLetramento no município ou estado (BRASIL, 2013, p. 12).

II. Materiais Didáticos e Pedagógicos: Este eixo é formado por conjuntos de materiais específicos para alfabetização, tais como: livros didáticos (entregues pelo PNLD) e respectivos manuais do professor; obras pedagógicas complementares aos livros didáticos e acervos de dicionários de língua portuguesa (também distribuídos pelo PNLD); jogos pedagógicos de apoio à alfabetização; obras de referência, de literatura e de pesquisa (entregues pelo PNBE); obras de apoio pedagógico aos professores; e tecnologias educacionais de apoio à alfabetização. Além de novos conteúdos para alfabetização, muda também a quantidade de materiais entregues às escolas, cujos acervos serão calculados por número de turmas de alfabetização e não por escola, possibilitando aos docentes e alunos explorar melhor os conteúdos (BRASIL, 2013, p. 12).

III. Avaliações: Este eixo reúne três componentes principais: avaliações processuais, debatidas durante o curso de formação, que podem ser desenvolvidas e realizadas continuamente pelo professor junto aos educandos. A segunda mudança refere-se à disponibilização de um sistema informatizado no qual os professores deverão inserir os resultados da Provinha Brasil de cada criança, no início e no final do $2^{\circ}$ ano e que permitirá aos docentes e gestores analisar de forma agregada essas informações e adotar eventuais ajustes. A 
terceira medida é a aplicação, junto aos alunos concluintes do $3^{\circ}$ ano, de uma avaliação externa universal, pelo INEP, visando aferir o nível de alfabetização alcançado ao final do ciclo, e que possibilitará às redes implementar medidas e políticas corretivas. Também neste caso, o custo dos sistemas e das avaliações externas será assumido pelo Ministério da Educação. Em 2013, o Ministério da Educação publicará um edital informando os critérios de premiação e reconhecimento aos professores, escolas e redes de ensino que mais avançarem na alfabetização das suas crianças, considerando os resultados aferidos nas avaliações (BRASIL, 2013, p. 13).

\section{Gestão, Controle Social e Mobilização: O} arranjo institucional proposto para gerir o Pacto é formado por quatro instâncias: i) um Comitê Gestor Nacional; ii) uma coordenação institucional em cada estado, composta por diversas entidades, com atribuições estratégicas e de mobilização em torno dos objetivos do Pacto; iii) Coordenação Estadual, responsável pela implementação e monitoramento das ações em sua rede e pelo apoio à implementação nos municípios; e iv) Coordenação Municipal, responsável pela implementação e monitoramento das ações na sua rede. Ainda neste eixo, destaca-se a importância do sistema de monitoramento que será disponibilizado pelo MEC, destinado a apoiar as redes e a assegurar a implementação de diferentes etapas do Pacto. Por fim, ressalta-se também a ênfase do MEC no fortalecimento dos conselhos de educação, dos conselhos escolares e de outras instâncias comprometidas com a educação de qualidade nos estados e municípios (BRASIL, 2013, p. 14).

Esses quatro eixos são articulados e deram ao PNAIC uma estrutura robusta para trabalhar com a complexidade do ato de alfabetizar. A adesão ao Pacto foi de mais de $90 \%$ dos municípios brasileiros, atingindo aproximadamente 300 mil professores que estiveram em formação específica para a alfabetização durante mais de cem horas anuais, de forma presencial e semi-presencial o que implicou a necessidade de um grande contingente que auxiliasse na formação de outros professores. Para dar conta desse grande contingente, optou-se pela formação de uma rede.

Um Formador, selecionado pela IES trabalha com 25 Orientadores de Estudo, selecionados pelos municípios, estes por sua vez trabalham com 25 Professores Alfabetizadores (o público alvo do projeto). Vê-se que uma estrutura como esta permite que se atinja, de forma presencial, uma quantidade significativa de pessoas. Com vistas a manter a concepção de alfabetização já discutida no documento Elementos Conceituais e Metodológicos para a Definição dos Direitos de Aprendizagem e Desenvolvimento do Ciclo de Alfabetização do Ensino Fundamental, e já enunciados por este, um conjunto de IES se dedicou a escrita do material de formação do PNAIC de Língua Portuguesa em 2012 e de Matemática em 2013. São esses cadernos, que dão movimento às discussões sobre currículo e sua implementação que terão destaque na sequência.

\section{Os Cadernos de Formação de Alfabetização Matemática do PNAIC}

No início do ano de 2013, um grupo formado por especialistas de diversas Universidades de todas as regiões do país, se reuniu com objetivo de estabelecer a escrita do material de formação de alfabetização matemática que seria utilizado para a formação dos professores alfabetizadores brasileiros no ano de 2014.

Esse processo que durou aproximadamente um ano e reuniu mais de uma centena de pessoas entre alunos da alfabetização, professores alfabetizadores da rede pública, leitores críticos, pesquisadores vinculados à Universidades e à Sociedade Brasileira de Educação Matemática, diagramadores e revisores, resultou na publicação de 8 cadernos de formação (enumerados abaixo de 1 a 8), um de apresentação e três cadernos de referência, a saber:

- Caderno de Apresentação

- Educação Matemática no Campo

- Educação Inclusiva

- Jogos na Alfabetização Matemática

- Caderno 1: Organização do Trabalho Pedagógico

- Caderno 2: Quantificação, Registros e Agrupamentos

- Caderno 3: Construção do Sistema de Numeração Decimal

- Caderno 4: Operações na Resolução de 
Problemas

- Caderno 5: Geometria

- Caderno 6: Grandezas e Medidas

- Caderno 7: Educação Estatística

- - Caderno 8: Saberes Matemáticos e Outros Campos do Saber

É importante salientar que os cadernos de formação foram estruturados com vistas a atender a um grupo de professores com uma característica específica. Trata-se de um grupo mediado por um Orientador de Estudo, que recebeu uma formação de um Formador mais experiente e que se responsabiliza em seu município de articular as discussões com outros professores alfabetizadores. De modo geral, esse Orientador de Estudo não é um especialista da área de Matemática e por vezes tem pouca experiência com formação de professores. Tal característica impôs a necessidade de estruturar o material com estratégias formativas que contemplassem textos curtos (com vistas a atender a demanda de uma formação em serviço) com uma linguagem adequada ao público alvo e que articulassem saberes necessários à docência: metodologia e conceitos matemáticos.

Dessa necessidade surgiu uma estrutura com seções descritas a seguir (BRASIL, 2014a, p.13-15):

- Iniciando a Conversa: Introduz as ideias gerais do caderno e apresenta seus objetivos.

- Aprofundando o Tema: Apresenta um conjunto de textos que permite conduzir reflexões variadas sobre o assunto. São textos de referência que, na medida do possível, precisam ser lidos fora do tempo e espaço dos encontros de formação. Nesses encontros, cabe a apresentação e/ou discussão coletiva das ideias principais de todos ou alguns desses textos. É importante salientar que, por vezes, esses textos apresentam informações para além dos conceitos que devem ser trabalhados em sala de aula, ampliando e aprofundando o repertório matemático do professor alfabetizador. Muitas vezes esses textos contêm indicações para a sala de aula ou incluem relatos de experiência articulados com as reflexões teóricas; outras vezes alguns textos vão se complementar, defender o mesmo ponto de vista com argumentos diferentes ou apresentar perspectivas diversas sobre um mesmo tema.
- Compartilhando: Apresenta sugestões de atividades para serem realizadas durante o encontro de formação. Esta seção tem como objetivos: ampliar e discutir conceitos matemáticos, refletir sobre relatos de experiência e sequências didáticas, elaborar ou adaptar encaminhamentos metodológicos sugeridos, refletir sobre os textos contidos na seção "Aprofundando o Tema", discutir sobre encaminhamentos sugeridos por livros didáticos, etc.

- Para Saber Mais: Esta seção apresenta a indicação de uma série de livros, artigos, itens e vídeos comentados e de fácil acesso para que o professor se aprofunde nos temas que julgar necessário.

- Sugestões de Atividades para os Encontros em Grupos: A seção encaminha possibilidades de trabalho para os encontros de formação. É preciso sempre ter em conta que, orientados pelas leituras e atividades, outros caminhos podem e devem ser seguidos.

- Atividades para Casa e Escola: Esta seção tem como principal objetivo potencializar uma das maiores qualidades do Pacto Nacional pela Alfabetização na Idade Certa: a reflexão sobre a realidade de sala de aula, pautada por discussões teóricas e pesquisas na área da Educação Matemática. Por isso, além de indicar a necessidade da leitura dos textos da seção "Aprofundando o Tema", sugere-se uma série de atividades em sala de aula no trabalho com as crianças: atividades que podem proporcionar elementos que sejam tomados como ponto de partida para o trabalho de formação no encontro seguinte.

Tendo em vista que o PNAIC de 2012-2013, teve a Linguagem como ênfase e adotou a terminologia e concepção do letramento, entendeu-se que seria adequado adotar-se terminologia semelhante que resultou em Alfabetização Matemática na Perspectiva do Letramento, evitando assim termos que, embora possuam respaldo acadêmico dentro da área de Educação Matemática, como letramento matemático e numeramento, pudessem desviar o foco do trabalho para discussões que somente possuem sentido legítimo no âmbito acadêmico.

No intuito de estabelecer as diretrizes do que se entende por Alfabetização Matemática na Perspectiva do Letramento, recorre-se as afirmações 
de Magda Soares (1998) quando discute as diferenciações entre alfabetizar e letrar:

O primeiro (alfabetizar) corresponderia à ação de ensinar aprender a ler e a escrever, enquanto o segundo (letrar) seria considerado como o estado ou a condição de quem não apenas sabe ler e escrever, mas cultiva e exerce as práticas sociais que usam a escrita.

(...) alfabetizar e letrar são duas ações distintas, mas não inseparáveis, ao contrário: o ideal seria alfabetizar letrando, ou seja: ensinar a ler e escrever no contexto das práticas sociais da leitura e da escrita, de modo que o indivíduo se tornasse, ao mesmo tempo, alfabetizado e letrado (SOARES, 1998, p. 47).

A concepção de Alfabetização Matemática na Perspectiva do Letramento do PNAIC pode ser obtida incorporando o diálogo com a Educação Matemática, afirmando que alfabetizar matematicamente corresponderia à ação de ensinar a escrita e leitura dos números, nomenclatura de polígonos, leituras de gráficos e tabelas, dentre outras noções. A perspectiva do letramento agrega o estado ou a condição de quem não apenas possui essas noções, mas cultiva e exerce as práticas sociais que as requerem. $\mathrm{O}$ ideal seria, então, alfabetizar letrando, ou seja, ensinar a ler e escrever no contexto das práticas sociais da leitura e da escrita, aí consideradas as noções matemáticas necessárias ao perfeito entendimento do texto.

O caderno de apresentação do PNAIC ressalta ainda que:

Entender a Alfabetização Matemática na perspectiva do letramento impõe o constante diálogo com outras áreas do conhecimento e, principalmente, com as práticas sociais, sejam elas do mundo da criança, como os jogos e brincadeiras, sejam elas do mundo adulto e de perspectivas diferenciadas, como aquelas das diversas comunidades que formam o campo brasileiro (BRASIL, Caderno de Apresentação, 2014a, p. 15).

Assim como nas considerações acima, o diálogo com os preceitos constantes no documento Elementos Conceituais e Metodológicos para a Definição dos Direitos de Aprendizagem e Desenvolvimento do Ciclo de Alfabetização do Ensino Fundamental é retomado em todo o material de formação.

Tal qual fizemos na seção anterior, tomaremos um dos cadernos com vistas a exemplificar o movimento do documento citado e os cadernos de formação. Elegemos o caderno 3: Sistema de Numeração Decimal.

Assim como os outros cadernos de formação, esse indica como objetivo os Direitos de Aprendizagem relativos ao eixo pertinente ao caderno:

O objetivo geral do caderno é fornecer subsídios que permitam ao professor encaminhar a construção do SND em situações lúdicas, de modo que a criança possa investigar as regularidades do sistema de numeração decimal para compreender o princípio posicional de sua organização.

Nestas situações, o professor deverá ser capaz de planejar suas aulas de modo que o aluno possa:

- reproduzir, em atividades orais e escritas, sequências numéricas ascendentes e descendentes a partir de qualquer número dado;

- elaborar, comparar, comunicar, confrontar e validar hipóteses sobre as escritas e leituras numéricas, analisando a posição e a quantidade de algarismos e estabelecendo relações entre a linguagem escrita e a oral;

- reconhecer regularidades do sistema de numeração decimal;

- ordenar, ler e escrever números redondos $(10,20,30, \ldots ; 100,200,300, \ldots ; 1000,2000$, $3000, \ldots)$;

- quantificar coleções numerosas recorrendo aos agrupamentos de dez em dez e demonstrar compreensão de que o dez está incluído no vinte, o vinte, no trinta, o trinta, no quarenta etc.;

- compreender o valor posicional dos algarismos na composição da escrita numérica, compondo e decompondo números;

- utilizar a calculadora, cédulas ou moedas do sistema monetário para explorar, produzir e comparar valores e escritas numéricas (BRASIL, 2014b, p.5).

Os encaminhamentos específicos para a construção do Sistema de Numeração Decimal (SND) é realizado pelos autores Cristiano Muniz, Eurivalda Ribeiro dos Santos, Sandra Maria Pinto Magina e Sueli Brito Lira de Freitas. Para auxiliar os alunos na construção das regras do SND os autores sugerem a utilização dos jogos Ganha Cem Primeiro, Gasta Cem Primeiro, Esquerdinha - quem primeiro tiver 100, Placar Zero, Agrupamento para Mudar de Nível (segundo a cor) e Qual a Representação do 
Número. Tais encaminhamentos estão ancorados no documento anteriormente citado que enfatiza a importância do ato de brincar e jogar nessa etapa de escolarização.

Vários professores alfabetizadores de todo o Brasil foram convidados a relatarem suas experiências para serem publicadas nos cadernos. Com vistas a exemplificar esse movimento, replicamos o relato de experiência da Professora Áurea Maria Jales Bicalho (Escola Classe 304 Norte - BRASÍLIA/DF).

\section{O JOGO “GANHA CEM PRIMEIRO” NO $1^{\circ}$ ANO}

A atividade foi aplicada por mim, em uma turma de $1^{\circ}$ ano, com 18 crianças presentes no dia.

A rotina da turma inclui, em um dos momentos da aula, "atividades diversificadas" (pintura, recorte e colagem, casinha, construções, jogos e massinha). Foi proposto ao grupo o jogo GANHA CEM PRIMEIRO.

As crianças escolheram a atividade que queriam participar. Quatro crianças escolheram participar desse jogo. Usamos dois dados com desenhos. No momento da contagem da quantidade obtida nos dados juntos, as crianças contavam os dois (apontando e recitando o número de quantidades) e pegavam a quantidade de palitos obtida nessa soma. Juntavam os soltinhos e contavam todos juntos, se tivesse dez ou mais, amarravam os dez.

Uma das crianças apresentou dificuldade ao comparar as quantidades obtidas por todos.

Um menino precisou de auxílio dos colegas e mediação da professora para amarrar os palitos. A frase "EU TE AUTORIZO A JOGAR" ajudou as crianças a esperarem seu momento de jogar e quem necessitou de mais tempo para se organizar garantiu esse tempo. Elas se sentiram poderosas e satisfeitas.

Essas pequenas e outras observações feitas por mim durante o jogo auxiliaram-me nas avaliações, planejamentos e possíveis intervenções, inclusive durante as jogadas, para a aprendizagem de cada uma das crianças da turma.

Outra observação que é pertinente fazer, é que, durante o jogo, a criança está brincando, livre da pressão de ter que dar uma resposta e o que ela faz e responde durante as jogadas não é uma resposta decorada, repetindo uma ideia imposta por alguém (BRASIL, Caderno 3, 2014b, p. 52).

A utilização de relatos de experiência cumpriu diversos objetivos como: ampliar a identificação do professor com o material, ilustrar diferentes realidades, disparar reflexões sobre práticas profissionais, articular a teoria e a prática, etc. Além desses objetivos e mais pertinente ao escopo do artigo, tratou-se de um momento ímpar de implementação curricular que fomentou discussões das possibilidades do trabalho com tais conteúdos em determinadas etapas da escolarização. Tais discussões, infelizmente, não foram retomadas ou sistematizadas quando da discussão da Base Curricular Nacional Comum que trataremos com maior detalhamento na sequência.

\section{Da Base Nacional Comum Curricular}

De acordo com a linha do tempo presente no portal da Base Nacional Comum Curricular ${ }^{3}$, o processo de construção do documento é disparado pela constituição de 1988 em seu artigo 210 e em 1996, pelo artigo $9^{\circ}$ da LDB e pelo Plano Nacional de Educação. Considera ainda em seu histórico os PCN de 1998 (Ensino Fundamental) e de 2000 (Ensino Médio) e as Diretrizes Curriculares Nacionais de 2010 a 2012.

O processo de escrita, propriamente dito, inicia em 2015, a partir da publicação da Portaria 592 que institui a Comissão de Especialistas para a Elaboração de Proposta da BNCC e finaliza em 2017 com a publicação da versão final, considerada a quarta versão do documento. De acordo com o portal, a elaboração da base recebeu, via plataforma digital, 12 milhões de contribuições.

O processo de alfabetização foi reduzido para os dois primeiros anos. De acordo com a Base:

Nos dois primeiros anos do Ensino Fundamental, a ação pedagógica deve ter como foco a alfabetização, a fim de garantir amplas oportunidades para que os alunos se apropriem do sistema de escrita alfabética de modo articulado ao desenvolvimento de outras habilidades de leitura e de escrita e ao seu envolvimento em práticas diversificadas de letramentos (BRASIL, 2017a, p. 57).

Embora sejam estabelecidas dez competências gerais para todas as etapas, a estrutura da Base é diferenciada para as diferentes etapas de Ensino: Educação Infantil, Ensino Fundamental e Ensino Médio ${ }^{4}$.

$\mathrm{Na}$ Educação Infantil são elencados seis "direitos de aprendizagem e desenvolvimento", a saber: Conviver, Brincar, Participar, Explorar, Expressar, Conhecer-se. São estabelecidos cinco "campos de experiência": O eu, o outro e o nós; Corpo, gestos e movimentos; Traços, sons, cores e 
formas; Escuta, fala, pensamento e imaginação; Espaços, tempos, quantidades, relações e transformações. Em cada campo de experiência são definidos "objetivos de aprendizagem e desenvolvimento" organizados em três grupos por faixa etária: Bebês (0 a 1 ano e 6 meses); Crianças bem pequenas ( 1 ano e 7 meses a 3 anos e 11 meses) e Crianças pequenas (4 anos a 5 anos e 11 meses).

O Ensino Fundamental está organizado em cinco "áreas do conhecimento" e nove "componentes curriculares":

- Linguagens: componentes curriculares de Língua Portuguesa, Arte, Educação Física, Língua Inglesa;

- Matemática: componente curricular de Matemática;

- Ciências da Natureza: componente curricular de Ciências;

- Ciências Humanas: componentes curriculares de Geografia e História;

- Ensino Religioso: componente curricular de Ensino Religioso.

O documento destaca as especificidades para os Anos Iniciais ( $1^{\circ}$ ao $5^{\circ}$ ano) e Anos Finais $\left(6^{\circ}\right.$ ao $9^{\circ}$ ano). Cada área do conhecimento estabelece "competências específicas de área cujo desenvolvimento deve ser promovido ao longo dos nove anos. Essas competências explicitam como as dez competências gerais se expressam nessas áreas" (BRASIL, 2017a, p.28).

Cada uma das "competências específicas" apresenta um conjunto de "habilidades", que são relacionadas a diferentes "objetos de conhecimento", ou seja, "conteúdos, conceitos e processos" que são organizados em "unidades temáticas".

No caso da área de matemática são elencadas as áreas temáticas de Números, Álgebra, Geometria, Grandezas e Medidas, Probabilidade e Estatística.

No primeiro ano são elencados 21 objetos de conhecimento, aos quais estão relacionadas 22 habilidades. Já no segundo ano temos 18 objetos de conhecimento, aos quais estão relacionadas 23 habilidades. Os objetos de conhecimento são similares entre os anos, garantindo alguma progressão. A seguir, Quadros 2 e 3, temos um excerto dos quadros dos dois primeiros anos com vistas a ilustrar a forma como são apresentadas as unidades temáticas, objetos de conhecimento e habilidades:

QUADRO 2: Exemplo de como as habilidades foram elencadas no Primeiro Ano

\begin{tabular}{|l|l|l|}
\hline Primeiro Ano & Objeto de Conhecimento & Habilidades \\
\hline Unidade Temática & $\begin{array}{l}\text { Sistema monetário brasileiro: } \\
\text { reconhecimento de cédulas e moedas. }\end{array}$ & $\begin{array}{l}\text { Reconhecer e relacionar valores de } \\
\text { moedas e cédulas do sistema monetário } \\
\text { brasileiro para resolver situações } \\
\text { simples do cotidiano do estudante. }\end{array}$ \\
\hline
\end{tabular}

Fonte: Excerto do Documento Brasil (2017a), adaptado pelo autor

QUADRO 3: Exemplo de como as habilidades foram elencadas no Segundo Ano

\begin{tabular}{|l|l|l|}
\hline Segundo Ano & Objeto de Conhecimento & Habilidades \\
\hline Unidade Temática & $\begin{array}{l}\text { Sistema monetário brasileiro: } \\
\text { reconhecimento de cédulas e moedas e } \\
\text { equivalência de valores. }\end{array}$ & $\begin{array}{l}\text { Estabelecer a equivalência de valores } \\
\text { entre moedas e cédulas do sistema } \\
\text { monetário brasileiro para resolver } \\
\text { situações cotidianas. }\end{array}$ \\
\hline
\end{tabular}

Fonte: Excerto do Documento Brasil (2017a), adaptado pelo autor

Tendo em vista que a matemática na Educação Básica é tratada de forma conjunta, a especificidade do trabalho pedagógico com os três primeiros anos ficou suprimida nas considerações gerais. No excerto abaixo observa-se a ausência do lúdico, o que ocorre em toda a discussão da área de Matemática:

O desenvolvimento dessas habilidades está intrinsecamente relacionado a algumas formas de 
organização da aprendizagem matemática, com base na análise de situações da vida cotidiana, de outras áreas do conhecimento e da própria Matemática. Os processos matemáticos de resolução de problemas, de investigação, de desenvolvimento de projetos e da modelagem podem ser citados como formas privilegiadas da atividade matemática, motivo pelo qual são, ao mesmo tempo, objeto e estratégia para a aprendizagem ao longo de todo o Ensino Fundamental. Esses processos de aprendizagem são potencialmente ricos para o desenvolvimento de competências fundamentais para o letramento matemático (raciocínio, representação, comunicação e argumentação) e para o desenvolvimento do pensamento computacional (BRASIL, 2017a, p. 264).

Nessa seção apresentou-se a Base, especificamente a discussão presente na parte relacionada à área de Matemática. Observam-se diferenças significativas entre os documentos anteriores à Base e a versão final, cabendo à próxima seção aprofundar essa discussão.

\section{Afastamentos, aproximações, ausências, alterações: uma Base sem passado}

A BNCC tem recebido críticas das mais diversas, de diferentes órgãos e em diferentes meios. O objetivo desse artigo é apontar o descolamento da Base de um movimento que há muito vinha se realizando e inferir algumas motivações desse processo que vêm se evidenciando com alterações do PNAIC e a criação de um novo programa, o Mais Alfabetização, parte da nova Política Nacional de Alfabetização (BRASIL, 2017b).

Em primeiro lugar é notório o afastamento das discussões da BNCC do âmbito acadêmico. Sem dúvida, há uma série de leituras críticas realizadas pelas Universidades, no entanto, observa-se uma nova composição de autores e críticos que dá lugar aos institutos e fundações. Um exemplo desse fato é a existência de um site próprio de defesa da Base (Movimento pela Base Nacional Comum) que congrega representantes de institutos e fundações.

Outra aproximação é com o INEP - Instituto Nacional de Estudos e Pesquisas Anísio Teixeira, órgão responsável pelas avaliações em larga escala no Brasil. Essa aproximação é feita durante a escrita, momento em que vários especialistas em avaliação participaram do processo.

$\mathrm{O}$ afastamento das Universidades, resulta em desconsiderar o movimento recente que resultou no documento Elementos Conceituais e Metodológicos para a Definição dos Direitos de Aprendizagem e Desenvolvimento do Ciclo de Alfabetização do Ensino Fundamental e no PNAIC. Constata-se que nas 472 páginas do documento da BNCC nada é falado sobre esses dois momentos. A terminologia "Direitos de Aprendizagem" é alterada na BNCC, sendo utilizada unicamente como estruturante da Educação Infantil, com significado distinto dos documentos anteriores.

A participação do INEP resulta em uma Base que reduz o que é considerado essencial, aproximando a BNCC das matrizes de avaliação de larga escala, tanto do ponto de vista quantitativo quanto do ponto de vista da fraseologia utilizada. Embora não se igualem, tendo em vista que as Matrizes de Referência são ainda mais restritivas, há uma evidente aproximação.

Na contramão de toda a discussão travada ao longo de quase uma década, a BNCC indica habilidades separadas por ano e reduz a alfabetização para dois anos. Com isso, desconstrói a ideia de Ciclo de Alfabetização, fragmentando o processo. Além disso, é importante observar a ausência de discussões sobre a importância do lúdico no processo de aprendizagem dos três primeiros anos, sobretudo para a alfabetização matemática, bem como a articulação entre esse processo e as práticas sociais. Tal movimento de distanciamento é criticado pela própria Base, quando afirma que "espera-se que a BNCC ajude a superar a fragmentação das políticas educacionais, enseje o fortalecimento do regime de colaboração entre as três esferas de governo e seja balizadora da qualidade da educação" (BRASIL, 2017a, p. 8).

A aproximação das avaliações de larga escala, a extinção da ideia de Ciclo de Alfabetização e a redução de três para dois anos no processo de alfabetização, indica um movimento meramente político, pois tudo depende de como entendemos o que é uma criança alfabetizada. Reiteradamente, o entendimento do Ministério tem sido o de considerar que uma criança alfabetizada é aquela que atinge níveis considerados adequados em leitura, escrita e matemática em avaliações de larga escala. Reduzindo-se o nível de exigência ou o número de descritores de tais avaliações pode-se reduzir o tempo destinado a alfabetização sem, no entanto, causar qualquer impacto efetivo no desenvolvimento real das crianças.

Com vistas a justificar as alterações realizadas no PNAIC e a criação do programa Mais Alfabetização, o MEC tem se utilizado dos dados das 
avaliações da Avaliação Nacional de Alfabetização, a ANA $^{5}$, - que não resultaram em mudanças significativas de índices. O que certamente deveria de se esperar, já que o PNAIC iniciou em 2012, a primeira ANA foi realizada em 2014 e a segunda em 2016. Ter uma expectativa de grande alteração nesse exíguo tempo trata-se de uma ingenuidade no campo da educação. Por outro lado, é digno de nota, que, depois de décadas em investimento nos anos iniciais em programas de formação de larga escala como o PROFA - Programa de Formação de Alfabetizadores, o GESTAR I (Programa da Gestão da Aprendizagem Escolar), o Pro-letramento e o PNAIC, somente essa etapa de ensino tenha superado a meta do IDEB em 2015.

Embora o programa Mais Educação esteja em fase inicial de concepção e implementação já se pode tecer algumas considerações. Tal programa tem como diferencial a contratação de um "assistente de alfabetização". De acordo com a apresentação do programa:

Todo professor alfabetizador regente contará como apoio de um assistente de alfabetização para o desenvolvimento de atividades pedagógicas, considerando os dados das avaliações e plano de trabalho definido pelo professor, escola e orientados pela secretaria (ação específica do PDDE - Programa Dinheiro Direto na Escola) (BRASIL, 2017b, p. 10).

$\mathrm{Na}$ sequência da apresentação, observa-se que o monitoramento se dará por meio de avaliações diagnósticas, formativas e somativas. Tais dados serão inseridos em plataformas digitais e utilizados para as formações dos professores e assistentes de alfabetização. Fecha-se um questionável ciclo de avaliação para a formação para a avaliação.

\section{Algumas considerações}

O objetivo desse artigo foi o de apresentar e discutir o processo de des-construção da Base Nacional Comum Curricular desde a escrita do documento Elementos Conceituais e Metodológicos para a Definição dos Direitos de Aprendizagem e Desenvolvimento do Ciclo de Alfabetização do Ensino Fundamental no ano de 2012 e do movimento formativo ocorrido nos anos de 2012 a 2017 disparado pelo Pacto Nacional pela Alfabetização na Idade Certa até a sua versão final (quarta versão) publicada em 2017, particularmente no que tange à alfabetização matemática.
O processo de afastamento das discussões realizadas no âmbito da construção do documento Elementos Conceituais e Metodológicos para a Definição dos Direitos de Aprendizagem e Desenvolvimento do Ciclo de Alfabetização do Ensino Fundamental e do PNAIC e a aproximação do ideário de avaliações de larga escala, resultaram em uma Base que desconsiderou boa parte das discussões e de determinados princípios já estabelecidos, como, por exemplo, o Ciclo de Alfabetização de três anos.

A Base é repetitiva em informar que não é "o currículo" da escola, mas que servirá de base a esse currículo. De maneira ainda mais enfática as Matrizes de Referência das avaliações de larga escala também deixam claro que não devem ser tomadas como referência curricular. No primeiro caso, pelo fato de que uma Base Nacional, sobretudo em um país com a diversidade cultural brasileira, deve dar margem a incorporar nos seus currículos elementos dessa diversidade. No segundo, pelo fato de que as Matrizes não contemplam todo o currículo, dado as limitações técnicas dos instrumentos utilizados.

No entanto, seja pela falta de equipe técnica, seja pela busca incessante de melhoria em índices de avaliações, o que se nota é a incorporação dos descritores como conteúdos curriculares e o mesmo efeito terá a Base, ao indicar como "habilidades" segmentos mínimos de conceitos e procedimentos como "Comparar números naturais de até duas ordens em situações cotidianas, com e sem suporte da reta numérica". (BRASIL, 2017a, p. 277). O efeito nos dois primeiros anos de educação é a redução do trabalho pedagógico àquilo que poderá ser medido e, aquilo que poderá ser medido é o que chamaremos de alfabetização. Nas palavras da presidente do INEP, Maria Inês Fini, “Avaliar não é apenas medir. Avaliar é medir e atribuir um juízo de valor para essa medida. E esse juízo de valor poderá ser atribuído com mais transparência a partir da aprovação da nova BNCC. Ela definirá melhor o que é o processo de alfabetização e em que ano escolar ela deverá ocorrer" (BRASIL, 2017b).

Conforme descrito na seção anterior, parte da Política Nacional de Alfabetização prevê o programa Mais Alfabetização. Apesar da concepção presente em tal programa, prevê-se a formação dos professores alfabetizadores em nível de mestrado, na modalidade profissional. Espera-se que anos de formação continuada no âmbito dos programas anteriores, e que a possibilidade, ainda não garantida, da relação Universidade-Escola nesses futuros mestrados profissionais, possam contribuir na 
formação de professores, pesquisadores, críticos, reflexivos no sentido de se insubordinarem criativamente $^{6}$ nas secretarias de educação, escolas e salas de aula.

\section{Notas}

1 Os termos I, A e C, se referem, respectivamente a Introduzir, Aprofundar e Consolidar. Apresenta um desenho de progressão que tem como objetivo preservar o princípio do Ciclo de Alfabetização.

2 É importante salientar que, ainda que não tenha havido uma extinção formal da RENAFOR, como é comum nas ações do Ministério, é fato que tal rede teve suas ações descontinuadas, embora se possa encontrar ações individuais de alguns centros. O Cecemca - Centro de Educação Continuada em Educação Matemática Científica e Ambiental da UNESP - Universidade Estadual Paulista, é um desses exemplos. O histórico de sua criação e ações pode ser encontrado em Cavamura (2017).

3 http://basenacionalcomum.mec.gov.br/linha-dotempo

4 A Base publicada em 2017 ainda não contempla o Ensino Médio, já que "Durante o processo de elaboração da versão da BNCC encaminhada para apreciação do CNE em 6 de abril de 2017, a estrutura do Ensino Médio foi significativamente alterada por força da Medida Provisória $n^{\circ} 446$, de 22 de setembro de 2016, posteriormente convertida na Lei $\mathrm{n}^{\circ} 13.415$, de 16 de fevereiro de 2017. Em virtude da magnitude dessa mudança, e tendo em vista não adiar a discussão e a aprovação da BNCC para a Educação Infantil e para o Ensino Fundamental, o Ministério da Educação decidiu postergar a elaboração - e posterior envio ao CNE - do documento relativo ao Ensino Médio, que se assentará sobre os mesmos princípios legais e pedagógicos inscritos neste documento, respeitando-se as especificidades dessa etapa e de seu alunado" (BRASIL, 2017a, p. 8).

5 Tais dados podem ser encontrados nas apresentações em pdf do Ministério da Educação, pois não se encontram ainda em documentos. $\mathrm{Na}$ apresentação que consta do link a seguir apresentase o programa Mais Educação e percebe-se a motivação para sua criação http://portal.mec.gov.br/index.php?option=com_d ocman \&view $=$ download $\&$ alias $=75191$-mais alfabetizacao-apresentacao-251017pdf\&category_slug=outubro-2017pdf \&Itemid $=30192$
60 termo insubordinação criativa foi trazido para a área de Educação Matemática pelas pesquisadoras Beatriz D'Ambrosio e Ceil Espasandin Lopes (2015). Ancorado nas discussões teóricas das pesquisadoras e seus referenciais é entendida aqui como uma determinada e possível leitura de diretrizes, sejam de documentos curriculares ou de políticas públicas de formação que mantenham princípios éticos no âmbito educativo, excluindose, portanto, interesses econômicos e empresariais.

\section{Referências}

BRASIL. Secretaria de Educação Básica. Base Nacional Comum Curricular. Brasília: MEC, SEB, 2017a.

BRASIL. Constituição da República Federativa do Brasil. Brasília, DF: Senado Federal: 1988.

Disponível em

http://www.planalto.gov.br/ccivil_03/constituicao/c onstituicaocompilado.htm. Acesso em: 16 de janeiro de 2018.

BRASIL. Secretaria de Educação Básica. Pacto Nacional pela Alfabetização na Idade Certa. Caderno de Apresentação. Brasília: MEC, SEB, 2014a.

BRASIL. Secretaria de Educação Básica. Pacto Nacional pela Alfabetização na Idade Certa. Caderno 3: Construção do Sistema de Numeração Decimal. Brasília: MEC, SEB, 2014b.

BRASIL. Secretaria de Educação Básica. Secretaria da Educação Básica. Elementos conceituais e metodológicos para definição dos direitos de aprendizagem e desenvolvimento do ciclo de alfabetização $\left(1^{\circ}, 2^{\circ}\right.$ e $3^{\circ}$ anos $)$ do ensino fundamental. Brasília: MEC, SEB, 2012.

BRASIL. Ministério da Educação. Lei de Diretrizes e Bases da Educação Nacional - Lei no 9.394/96. Brasília, DF: Senado Federal: 1996. Disponível em http://www.planalto.gov.br/ccivil_03/leis/L9394.ht m. Acesso em: 16 de janeiro de 2018.

BRASIL. Lei $n^{\circ} 13.005$, de 25 de junho de 2014. Aprova o Plano Nacional de Educação - PNE e dá outras providências. Brasília, DF: Senado Federal: 2014c. Disponível em:

https://www.planalto.gov.br/ccivil_03/_ato2011- 
2014/2014/lei/113005.htm. Acesso em: 16 de janeiro de 2018.

BRASIL. Secretaria de Educação Básica. Mec anuncia Política Nacional de Alfabetização para reverter estagnação na aprendizagem. Brasília: MEC, SEB, 2017b. Disponível em http://portal.mec.gov.br/component/content/article?i $\mathrm{d}=56321$. Acesso em: 16 de janeiro de 2018 .

BRASIL. Secretaria de Educação Básica. Pacto Nacional de Alfabetização na Idade Certa: livreto explicativo. Brasília: MEC, SEB, 2013.

BRASIL. Secretaria de Educação Básica. Política Nacional de Alfabetização. Brasília: MEC, SEB, 2017c. Disponível em http://portal.mec.gov.br/index.php?option=com_doc man $\&$ view $=$ download $\&$ alias $=75191$-mais - alfabetizacao-apresentacao-251017pdf\&category_slug=outubro-2017pdf\&Itemid=30192. Acesso em: 16 de janeiro de 2018.

CAVAMURA, A. E. Formação Continuada de Professores de Matemática na Década de 2000: um olhar para o Centro de Educação Continuada em Educação Matemática. Científica e Ambiental (Cecemca). (Dissertação de Mestrado), IGCE UNESP/Rio Claro - SP. 2017. 284 fls.

D'AMBROSIO, B. S.; LOPES, C. E. Insubordinação Criativa: um convite à reinvenção do educador matemático. Bolema, v. 29, n. 51, p. 1 17, 2015.

SOARES, M. Um tema em três gêneros. 1. Ed.. Belo Horizonte: Ed. Autêntica, 1998.

\section{Sobre o autor}

Emerson Rolkouski é Licenciado em Matemática e Mestre em Educação pela Universidade Federal do Paraná, doutor em Educação Matemática pela Universidade Estadual Paulista. Atualmente é professor associado no Departamento de Expressão Gráfica, Setor de Ciências Exatas da Universidade Federal do Paraná e professor do Programa de Pós Graduação em Educação em Ciências e em Matemática onde desenvolve pesquisas na área de Educação Matemática e Políticas Públicas.

Recebido em janeiro de 2018.

Aprovado em março de 2018. 